\title{
Food deprivation and responsiveness for lateral hypothalamic stimulation*
}

\author{
SUZANNE BECKER ROSE, JAMES P. HUNSICKER, and LARRY D. REID \\ Bradley University, Peoria, Ill, 61606
}

Rats were run for hypothalamic intracranial stimulation (ICS) every day for 32 days in an alley maze. On one-half of the days, rats were deprived of food for $24 \mathrm{~h}$. Rats ran the first trial of a day faster for ICS when food deprived. Running speed remained relatively constant across testing when deprived, but slowly increased across the days when rats were not deprived. Range of responsiveness across deprivation-nondeprivation conditions was small compared to range of responsiveness across $\mathrm{Ss}$, indicating that deprivation itself was a minor determinant of the reinforcing value of ICS.

Despite the tremendous volume of research following Olds \& Milner's (1954) discovery of reinforcement from intracranial stimulation (ICS), there are few systematic investigations of the variability of responsiveness among groups of self-stimulating Ss. Specification of the variability and stability of responsiveness for ICS is a prerequisite for sound interpretation of selected studies and provides an appropriate background for theoretical statements.

When rats with electrode sites closely grouped within the lateral hypothalamus are tested under a variety of conditions, they show a wide diversity of responding. Wide differences among Ss become apparent with tasks that demand spaced trials. When alley-maze trials are spaced by $24 \mathrm{~h}$ of no ICS, Ss differ in their running for ICS (West, Hunsicker, \& Reid, 1971). Consequently, when it was determined that more data were needed on the effects of food deprivation on responding for hypothalamic ICS, the choice of tests was spaced trials in an alley maze.

Several studies (e.g., Olds, 1958; Deutsch \& DiCara, 1967) have investigated the effects of food deprivation on responsiveness for ICS. This study confirms that food deprivation can augment responsiveness for hypothalamic ICS; however, these data lead to somewhat different conclusions than previous data.

\section{SUBJECTS}

The Ss were 12 adult male albino rats fitted, in standard ways, with chronically indwelling electrodes to stimulate the lateral hypothalamus. The commercially made electrodes (Plastic Products, Model 303) were bipolar and stainless steel, insulated except at the cross-section of the

*This study was supported by the Board for Research, Bradley University, which administers NSF Grant GU $\mathbf{3 3 2 0 .}$ stimulating tip. Each pole of the electrode was about $0.2 \mathrm{~mm}$ in diam and separated from the other pole only by the insulation. Modal stereotaxic coordinates were $3.5 \mathrm{~mm}$ posterior to bregma, $1.6 \mathrm{~mm}$ lateral to the midline, and $8.25 \mathrm{~mm}$ from the top of the skull, with the cranium arranged so that bregma and lambda were on the same horizontal plane. Subsequent direct inspection of frozen sections of brains indicated that all stimulation sites fell within a block of tissue with a medial boundary the plane of the fornix and a lateral boundary $2.0 \mathrm{~mm}$ from the midline. The ventral boundary was nearly the base of the hypothalamus and the dorsal boundary was a plane through the top of the dorsomedial $n$. The anterior and posterior boundaries were 4.620 and $3.750 \mathrm{~mm}$, respectively, from the interaural plane as indexed by the atlas of Konig \& Klippel (1963). This placement of electrodes in our laboratory typically yields a wide range of responding, and these 12 Ss correspond rather closely to the range of maze performance we typically get with these placements and similar procedures.

\section{APPARATUS}

The apparatus was a C-shaped runway, $305 \mathrm{~cm}$ long, $12 \mathrm{~cm}$ wide, and $29 \mathrm{~cm}$ deep. The startbox had a sliding gate, and the goalbox was equipped with a Scientific Prototype rat lever. A timer started when the gate opened and stopped with the first leverpress. Another timer started at the first leverpress and stopped with the 10th. ICS $(60-\mathrm{Hz}$ sine waves) varied from 30 to 60 microA (peak to peak) across Ss and up to $0.5 \mathrm{sec}$ duration ad lib for each leverpress.

\section{PROCEDURE}

Each $\mathbf{S}$ was tested in the goalbox of the runway to determine whether or not ICS was reinforcing. Those Ss that did not obtain at least a rate of 12.5 presses/min on the first test were discarded (4 out of 16 did not meet criteria). For the remaining $\mathrm{Ss}$, an intensity of ICS that sustained rapid leverpressing was selected. The selected intensity was also the intensity that produced the least seizures and forced motor movement.

The Ss were then trained to run the maze for the opportunity to press for the selected ICS. To stabilize performance before the testing trials, training continued for 5 consecutive days of five trials a day, 10 ICSs a trial, with 30 -sec intertrial intervals and 24 -h intersession intervals. If time between the opening of the startbox and the first leverpress exceeded $100 \mathrm{sec}, \mathrm{S}$ was placed near the lever and allowed to press for 10 ICSs and running time was recorded as 100 sec. During preliminary testing, food and water were constantly available in the home cages.

After selection of Ss and intensity of ICS and maze training, Ss were run daily for 32 days for five trials a day under the same regimen as preliminary training, with the exception that Ss were tested either after $24 \mathrm{~h}$ of food deprivation or after $24 \mathrm{~h}$ of free feeding. Counterbalancing (ABBA) was used to arrive at a schedule of nondeprivation or deprivation testing. Directly following the first day of deprivation and testing, Ss were given about $12 \mathrm{~g}$ of Lab Chow to maintain a schedule of $24 \mathrm{~h}$ of deprivation. Weight of Ss ranged from 300 to $427 \mathrm{~g}$ during nondeprivation testing and from 272 to $392 \mathrm{~g}$ during deprivation testing. After the final testing session, Ss were sacrificed, perfused, and slices of the brain inspected to determine more specifically the site of stimulation.

Data of the time elapsed between the first ICS and the 10th ICS at the end of each run were much more homogeneous than running times, with all Ss pressing rapidly for ICS once they had begun. This observation confirms a previous conclusion (West et al, 1971) that differential responsiveness among a group of self-stimulators is more apparent on discrete trial performance, such as running for ICS, than with rate of pressing once $\mathrm{Ss}$ have begun pressing. Since data of pressing times parallel those of running times, and since running times are more sensitive measures, only running times were analyzed extensively and are reported. Inspection of the data of the second, third, and fourth trial running times led to the conclusion that data of fifth trials could accurately represent all data of trials after the first trial running times.

As an aid in summarizing the balance of the data (running times on first and fifth trials of a day), analyses of variance (ANOVA) were done with data grouped according to a 12 by 2 


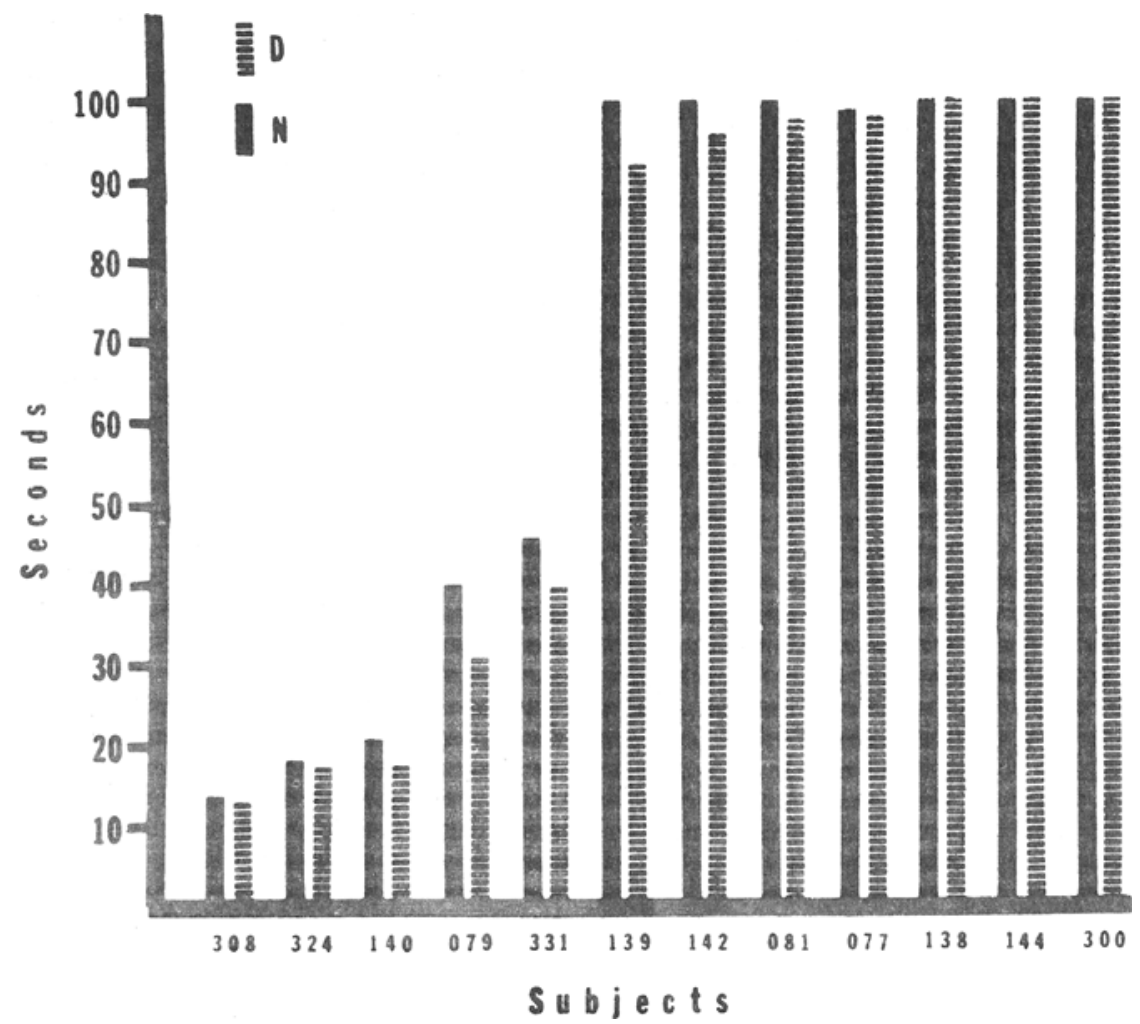

Fig. 1. Mean first trial running time for each $S$ when either food deprived or not food deprived. Each bar represents the mean of 16 trials. preceded by only $30 \mathrm{sec}$ of no ICS, was run generally under $10 \mathrm{sec}$ ( $F$ for Ss in the fifth trial $=109.8, \mathrm{df}=$ $11 / 336, p<.001)$.

The first trial running times of a day were sensitive to the deprivation condition $(F=24.4, \mathrm{df}=1 / 336$, $\mathrm{p}<.01$ ), but fifth trial running times were not $(F=0.4$, df $=1 / 336$, n.s. $)$. Also from Fig. 1, it can be seen that within-S change in running times due to deprivation is far less than the differences in running times between Ss. Every $\mathbf{S}$ ran on the average faster when deprived, with the exception of three Ss that failed to run any first trial, but each $S$ ran at about the time it ran when not deprived. Furthermore, the Deprivation by $S$ interaction was not a reliable source of variance for first trial running times ( $F$ $=1.26, \mathrm{df}=11 / 336$, n.s. .

Figure 2 shows the mean running times on first trial of a day, with each of 16 different tests of deprivation or nondeprivation plotted consecutively for each condition. From Fig. 2, it is apparent that Ss ran, in general, faster on days of deprivation than on days without deprivation. Also, as testing continued, there was a trend for mean running times for the nondeprived condition to increase; the $F$ for the main effect of first block-second block was $19.4, \mathrm{df}=1 / 336, \mathrm{p}<.01$. by 2 factorial design, with Ss, deprivation condition, and first block-second block of tests as factors, respectively. Each $\mathbf{S}$ was treated as a separate factor in order to assess contributions to the variance due to $S s$ and because each self-stimulation site is probably unique in its fine detail. All times of trials under deprivation were grouped together and compared to all times of trials not deprived regardless of the order in which they were run. To summarize grossly the effects of continued testing on performance, all data of the first 16 days of testing were grouped together and data of the last 16 days were grouped as a main effect in the ANOVA. Consequently, $\mathrm{F}$ ratios summarize variance attributable to the factors of Ss, state of deprivation, a block effect reflecting whether trials were of the first or second half of testing, and the interaction of these main effects.

\section{RESULTS}

Figure 1 illustrates the variability among Ss on first trial running times $(\mathrm{F}$ for $\mathrm{Ss}=167.5, \mathrm{df}=11 / 336$, $\mathbf{p}<.001$ ). As in a number of our studies (e.g., West et al, 1971), trials preceded by long periods of no ICS were more variable, with some Ss always running in about $10-20 \mathrm{sec}$ and some never running in the 100 -sec time limit. The fifth trial of a day,

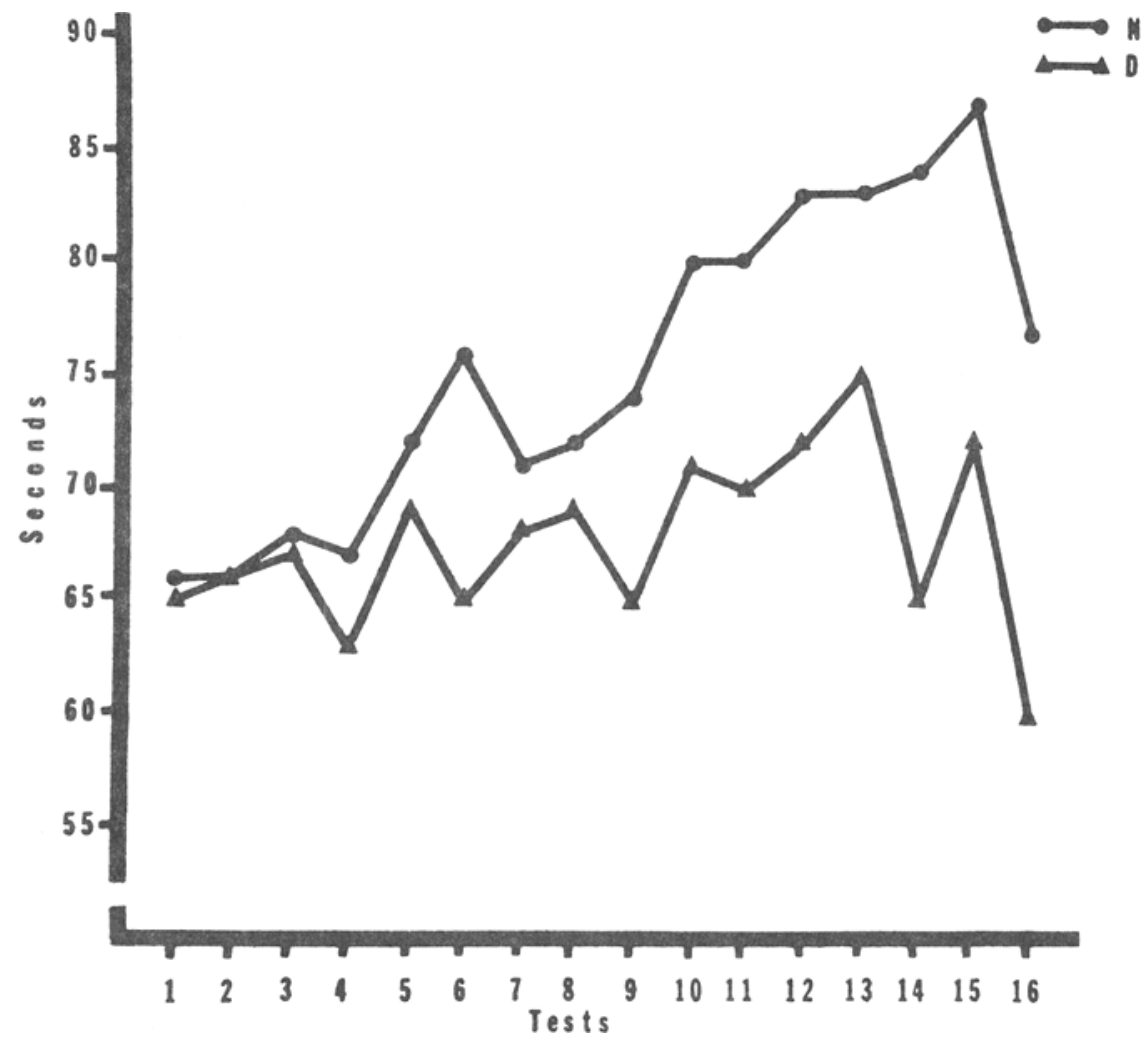

Fig. 2. Mean first trial running time for all Ss on each day of testing. The tests with food deprivation and nondeprivation followed one another in an NDDN order, and the abscissa is the order of tests under each condition. 
Increased running times with continued testing were primarily due to the data of three $\mathrm{Ss}(25 \%$ of $\mathrm{N})$ contributing markedly to a Ss by Block factor, with $F=17.8, \mathrm{df}=$ $11 / 336, p<.01$.

Fifth trial running times had a tendency to decrease as testing continued (block main effect $F=17.7$, $\mathrm{d} \mathrm{f}=1 / 336, \quad \mathrm{p}<.01)$. Although deprivation did not uniformly or reliably decrease fifth trial running times, it did lead to small but reliable increases in some Ss (Deprivation by Ss $F=4.2, \mathrm{df}=11 / 336, \mathrm{p}<.01)$. The triple interactions were not reliable sources of variance for either the analysis of first or fifth trial running times.

$\mathrm{H}$ istological verification showed that Ss 308 and 324 , showing fastest running times, had electrode tips well within the medial forebrain bundle lateral hypothalamus. Among Ss showing the longest first trial running times, there were electrode tips situated so that optic tract may have received some stimulation, particularily if it can be assumed that area of activation is a $1-\mathrm{mm}$ sphere at the tip of the electrode. These observations are not at variance with the notion that fastest first trial running results from homogeneous activation of medial forebrain bundle.

\section{DISCUSSION}

Perhaps the most significant finding was the result indicating that food deprivation augmented the incentive and reinforcement value of lateral hypothalamic stimulation but did not determine that value. There was no instance in which a nonresponding $S$ was turned into an eagerly responding $S$ by food deprivation. The effect of food deprivation was to change responsiveness within a relatively narrow range regardless of the site of stimulation. With other sites not sampled here, there, of course, remains the possibility of more dramatic effects with deprivation; however, electrodes were scattered throughout the lateral hypothalamus. With these Ss, then, the primary determinant of responsiveness to ICS remains that portion of the variance attributable to a $\mathrm{S}$ factor, which in turn is most likely related to variations in exact stimulation. This conclusion of the overwhelming importance of exact stimulation to the determination of exact responsiveness for ICS is the same conclusion that other data have indicated (e.g., West et al, 1971; Westcott, Reid, \& Wasden, 1969).

Determination of exact ICS is complicated, and conventional histological inspection of brain slices for extent of electrode penetration gives only a gross approximation of the tissue stimulated. Parameters of the electrical stimulation, including the exact shape of the electrode tips, interact with site of ICS to determine the effect of a particular ICS. Food deprivation uniformly augmented the incentive value of ICS, or maintained the incentive value of ICS in comparison to responding when not food deprived, except in those Ss that did not run under any condition within the time limit. It is obvious that there is some relationship between incentive value of intracranial reinforcement and food deprivation, although after Ss have begun stimulation, the relationship is much weaker. The data lead to the interpretation that there exists a relatively uniform homogeneous system within the hypothalamus, probably associated with medial forebrain bundle, the activity of which is reinforcement (and related states). The activity of the system is modulated by deprivation states, present activities of the organism, state of the tissue influenced by previous ICS, and previous experience.

The conception of a single "reward system" is close to Olds's (1969) and
Stein's (1964) conceptualizations, but at variance with Deutsch's (Deutsch \& Deutsch, 1966). Deprivation, from Deutsch's point of view, should produce more dramatic changes in responsiveness inasmuch as deprivation is the condition that makes ICS a reward, except for previous ICS or other deprivations. Yet in these Ss, deprivation merely augmented responsiveness for ICS; it did not shift that responsiveness dramatically. Deprivation did not supply a missing motivation; it augmented or maintained incentive value of ICS. A single system, the activity of which is modulated by deprivation but does not depend solely on deprivation, more closely fits data presented here.

\section{DEUTSCH REFERENCES}

P. Ill: Dorsey Press, 1966

DEUTSCH, J. A., \& DiCARA, L. Hunger and extinction in intracranial self-stimulation. Journal of Comparative \& Physiological Psychology, 1967, 63, 344-347.

KONIG, J. F., \& KLIPPEL, R. A. The rat brain: $A$ stereotaxic atlas. Baltimore: Williams \& Wilkins, 1963

OLDS, J. Effects of hunger and male sex hormone on self-stimulation of the brain. Journal of Comparative \& Physiological Psychology, 1958, 51, 320-324.

OLDS, J. The central nervous system and the reinforcement of behavior. American Psychologist, 1969, 24, 114-132.

OLDS, J., \& MILNER, P. M. Positive reinforcement produced by electrical stimulation of septal area and other areas of rat brain. Journal of Comparative \& Physiological Psychology, 1954, 47. 419-427.

STEIN, L. Keciprocal action of reward and punishment mechanisms. In $R, G$. Heath (Ed.). The role of pleasure in behavior. New York: Hoeber, 1964. Pp. 113-139. WEST, G. L., HUNSICKER, J. P., \& REID, L. D. Performance differences for intracranial reinforcement as a function of recency and number of stimulations. Communications in Behavioral Biology, $1971,6,171-176$.

WESTCOTT T W REID, L. D., \& WASDEN, $R$. E. Intracranial reinforcement: Performance decrement as a function of stimulus parameters. Psychonomic Science, 1969, 15, 147-149. 